\title{
HealthAffairs
}

At the Intersection of Health, Health Care and Policy

Cite this article as:

Richard Grol, Paul Giesen and Caro van Uden

After-Hours Care In The United Kingdom, Denmark, And The Netherlands: New Models Health Affairs, 25, no.6 (2006):1733-1737

doi: 10.1377/hlthaff.25.6.1733

The online version of this article, along with updated information and services, is available at:

http://content.healthaffairs.org/content/25/6/1733.full.html

For Reprints, Links \& Permissions:

http://healthaffairs.org/1340_reprints.php

E-mail Alerts : http://content.healthaffairs.org/subscriptions/etoc.dtl

To Subscribe: http://content.healthaffairs.org/subscriptions/online.shtml

Health Affairs is published monthly by Project HOPE at 7500 Old Georgetown Road, Suite 600, Bethesda, MD 20814-6133. Copyright (C 2006 by Project HOPE - The People-to-People Health Foundation. As provided by United States copyright law (Title 17, U.S. Code), no part of Health Affairs may be reproduced, displayed, or transmitted in any form or by any means, electronic or mechanical, including photocopying or by information storage or retrieval systems, without prior written permission from the Publisher. All rights reserved. 


\title{
UPDATE: INTERNATIONAL REPORT
}

\section{After-Hours Care In The United Kingdom, Denmark, And The Netherlands: New Models}

\author{
Integrating telephone consultations, triaging, and physician visits or \\ house calls offers a promising model for after-hours care.
}

\section{by Richard Grol, Paul Giesen, and Caro van Uden}

ABSTRACT: There are indications that after-hours care in some countries is of poor quality. European after-hours care is shifting away from individual and group practices with local after-hours call schedules toward large-scale after-hours care services. Experiences with primary care cooperatives in three countries show that this model can lighten physicians' workloads, reduce the number of face-to-face contacts, reduce use of emergency services and hospital admissions, and lower costs. Most patients accept these new models but are dissatisfied if they expect to see a physician. Local or regional integration of all emergency services seems to be the most promising model for after-hours care. [Health Affairs 25, no. 6 (2006): 1733-1737; 10.1377/hlthaff.25.4.1733]

A POLICY ISSUE RECEIVING increased attention in many countries is how to organize and provide primary care efficiently and effectively outside office hours. Policymakers and patients worry increasingly about access to and the quality and safety of care provided after hours, especially in urgent situations. Patients, particularly in the United States and Canada, have reported difficulties with access to good and timely after-hours care. ${ }^{\text {I }}$ Use of emergency departments (EDs) is higher in countries where patients report the most difficulty getting same-day and after-hours care from their regular doctors, which has implications for the cost, efficiency, and continuity of care. ${ }^{2}$

The main models used for after-hours pri- mary care so far have been individual practices or practices collaborating in local on-call schedules to take care of each other's patients after hours. However, Western countries are now shifting away from such primary care systems toward large-scale organizations. In after-hours care, there is a sharp increase in telephone triage and consultation, with new types of providers taking over tasks from doctors. ${ }^{3}$

The main reasons for reorganizing afterhours care are (1) physicians' increasing workloads as a result of the increase in nonurgent demands and the complexity of health care problems and (2) the shortage of physicians in some countries. ${ }^{4}$ Furthermore, the changes are an attempt to accommodate physicians' desire for greater separation of work and private life;

Richard Grol (r.grol@kwazo.umcn.nl) is a professor of quality of care at the Centre for 2uality of Care Research (WOK), Radboud University Nijmegen Medical Center, in the Netherlands. Paul Giesen is a medical doctor at WOK. Caro van Uden is a research fellow in the Department of Integrated Care, University Hospital Maastricht, in the Netherlands. 
sometimes the reforms are also aimed at reducing health care costs. ${ }^{5}$ Policymakers in the United States and Canada, where access to good after-hours care has proved difficult, might learn from experiences in some European countries with innovative models of after-hours primary care. ${ }^{6}$

Six models for after-hours care are used in various countries. ${ }^{\top}$ (1) Practice-based services: Family physicians within one practice or organized in a group of practices look after their patients on out-of-hours schedules. (2) Deputizing services (outsourcing): Commercial companies employing doctors and nurses take over the provision of after-hours care. (3) Hospital EDs: EDs provide primary care by taking care of health problems after office hours. (4) Telephone triage and advice centers: These are centers that patients can phone to receive telephone advice after hours. (5) After-hours primary care centers: These are walk-in centers for face-to-face contact with a doctor or nurse. (6) Primary care cooperatives: General practitioners (GPs) in a region from several groups, supported by additional personnel, provide after-hours primary care mostly in nonprofit, large-scale organizations, which include telephone triage and advice, offices for face-toface contact, and house calls.

In this paper we discuss cooperative models that have evolved in the United Kingdom, Denmark, and the Netherlands over the past decade.

\section{Study Findings}

United Kingdom. Between 1952 and 1989, the proportion of U.K. family physicians who worked alone after hours decreased from 43 percent to 11 percent, evidence of the growth in shared practice call schedules. Furthermore, from the late 1950s onward, deputized commercial services began to expand to cover most large U.K. cities. In 1989 these services were responsible for 46 percent of house calls made at night. ${ }^{8}$ From the early 1990s onward, primary care cooperatives have mushroomed, fueled by physicians' dissatisfaction with on-call commitments and the level of financial support provided by the government.
Cooperatives vary widely in their composition and patterns of service delivery. Most provide telephone consultation, face-to-face contact at walk-in centers, and house calls, but it has become more and more common for them to provide telephone advice only. ${ }^{9}$

Nurses versus receptionists. Val Lattimer conducted a well-designed randomized controlled trial (RCT) in the United Kingdom that compared telephone-advice services within a primary care cooperative (using trained nurses and computerized decision support) with the average cooperatives, where receptionists answer the telephone but cannot dispense advice or help. ${ }^{10}$ In the new nurse-led system, nurses were able to handle about half of all calls without referring them to a physician. In this system, there were 69 percent fewer telephone contacts with doctors, 38 percent fewer patients attending the walk-in clinic, and 23 percent fewer house calls. No differences were found in hospital admissions or mortality within seven days, and costs were considerably lower than they had been.

Physician-led cooperative. Another controlled study in the United Kingdom shows that the introduction of a physician-led cooperative did not lead to changes in the use of accident and emergency (A\&E) services or patient satisfaction."

Primary Care Trusts and NHS Direct. However, after the introduction of the new contract in the United Kingdom in 2004, almost all physicians opted to relinquish the responsibility of twenty-four-hour care. Primary Care Trusts (local entities that organize services) now have the responsibility to come up with solutions for after-hours care. The solutions adopted differ widely between trusts. Some assign the responsibility to private companies, some to cooperatives, and some to hospitals. Some use National Health Service (NHS) Direct for triage and advice service as a first step. This service, set up by the NHS in the 1990s, is freely accessible to all residents and provides telephone triage and advice by trained nurses who use (computerized) decision support. Around 2000, about 65 percent of U.K. residents made use of this service. ${ }^{12} \mathrm{~A}$ before-and- 
after evaluation of NHS Direct shows a small but significant decrease in the use of family practice cooperatives, but no change in the use of $A \& E$ and ambulance services. ${ }^{13}$ A more recent evaluation of the impact of NHS Direct on 104 primary care cooperatives, 75 ambulance services, and 170 emergency services during 1998-2001 shows a reduction of 8 percent per year in the number of calls to the cooperatives, but no reduction of the use of $A \& E$ and ambulance services, as expected. ${ }^{14}$

Integrated systems. In some U.K. regions, the after-hours services of thirty-one physician cooperatives and A\&E services have been integrated and work closely with NHS Direct..$^{15}$ In this model, NHS Direct performs the triage, which results in either telephone advice, a doctor on the phone, face-to-face contact with a doctor or a nurse in a walk-in clinic, or referral to emergency services (ambulance, A\&E, mental health, and so forth). Complete integration has been achieved by 68 percent of the cooperatives. However, access has not improved: Most patients had to make at least two phone calls to NHS Direct and then had to wait for a nurse to return the call. Fewer calls with advice were completed than was expected, while the calls to ambulance services greatly increased at some sites.

Denmark. In 1992, Denmark changed its system for after-hours primary care from local groups to large organizations covering an entire county (Denmark has sixteen counties with 50,000-600,000 inhabitants each). ${ }^{16}$ The cooperatives are organized by family physicians and regional health insurers, with the physicians responsible for the financial results. After hours, all patients have direct, free-ofcharge access to a fully trained and licensed family physician, who does triage and gives advice. Patients can be seen at the center as well. During house calls, physicians stay in touch with the triage center via computers and cell phones; they can get information about previous patient contacts, tests ordered, and the best medication to prescribe. The introduction of the new system greatly reduced physicians' workloads and changed the proportion of telephone consultations and house calls. ${ }^{17}$ Bjarne
Luhr Hansen and Anders Munck, evaluating the Danish cooperative model, saw an increase in telephone consultations after introduction of the new model (from 22 percent in 1991 to 54 percent in 1995) and a decrease in house calls (from 57 percent to 19 percent).$^{18}$ However, the proportion of patients who were dissatisfied with the service increased in the first year-from 13 percent in 1991 to 28 percent in 1992, with a reduction to 19 percent in 1995. ${ }^{19}$ The proportion of physicians working more than ten hours a week after hours decreased from 50 percent in 1990 to 10 percent in 1993.20

- The Netherlands. Until recently, most after-hours primary care in the Netherlands was delivered by collaborating practices via local call schedules. In a very short time (between 2000 and 2003), the landscape of afterhours care changed almost completely. ${ }^{21} \mathrm{Al}-$ most all physicians now participate in largescale, after-hours, primary care cooperatives. After-hours care in the Netherlands is defined as care delivered from 5 p.m. to 8 a.m. on weekdays and from 5 p.m. on Friday to 8 a.m. on Monday. There are about 120 of these cooperatives with generally 40-120 family physicians taking care of populations of 50,000-500,000 who live as far as twenty miles away. Patients seeking urgent help after hours are encouraged to phone the cooperative, but they can also visit the ED of the local hospital or phone the national emergency number: 85 percent use the cooperative's telephone number. Patients must access the cooperative via a single regional telephone number before attending (the first contact is by telephone in approximately 95 percent of cases). Trained nurses do the telephone triage, supervised by family physicians, who are consulted in case of doubt and who check and authorize all calls handled by the triage nurses. At all primary care cooperatives in the Netherlands, national (evidencebased) triage protocols and guidelines are available for triage nurses to use during calls. Some cooperatives have started using computer-based decision-support systems. Generally, 20 percent of the requests for help are classified as "urgent."22 Telephone advice is provided about 50 percent of the time; face-to- 
face contact at the cooperative, about 35 percent; and a house call, about 15 percent. About 6 percent of patients are referred to a hospital.

Patient satisfaction. Patients who received only telephone consultations from nurses were less satisfied with the service than patients who received a face-to-face consultation at the cooperative or a house call..$^{23}$ Also, relatively many patients were dissatisfied with information about how the after-hours cooperative was organized. Patients who did not expect, but only got, telephone advice gave the most negative evaluations. ${ }^{24}$

House calls. Chauffeured cars are available for doctors who make house calls. These cars are equipped with communication equipment, oxygen, infusion drips, and automatic defibrillators. ${ }^{25}$ Chauffeurs are trained to assist the doctor. Most house calls are provided for very urgent or moderately urgent health problems, although 22 percent are provided for nonurgent problems. ${ }^{26}$ About 90 percent of house calls are for people age sixty-five or older. The most common diagnoses at house calls at a large cooperative in a mixed urban-rural area were heart problems (18 percent); lung problems (17 percent); unspecified problems (17 percent); digestive problems (12 percent); and musculoskeletal problems (10 percent).

Hospital services. When home treatment is not possible, the family physician calls an ambulance for transport to the hospital. About 21 percent of all house calls were referred to the hospital in 2003. ${ }^{27}$ For very urgent problems, there is intensive collaboration with the ambulance services; for life-threatening problems, if all ambulances are occupied, the primary care cooperative car makes the visit and, if possible, transports the patient. ${ }^{28}$

Physicians' workload and satisfaction. Research in the Netherlands has shown that physicians' workloads diminished after the new out-ofhours organization was introduced, and their job satisfaction increased. ${ }^{29}$ The total number of on-call hours fell from approximately nineteen hours a week before the cooperatives to four hours a week in 1999. ${ }^{30}$

Progress report. Discussion about the future of after-hours care in the Netherlands favors a model in which hospital EDs and primary care cooperatives work together intensively and even integrate some services. Evaluation of this model in the Maastricht region showed a 25 percent increase in contacts with primary care, a 53 percent reduction in contacts with emergency care, 89 percent fewer self-referrals to the ED, a 12 percent reduction in ambulance calls, and 34 percent fewer hospital admissions. ${ }^{31}$ Patients appeared to be satisfied with this approach. ${ }^{32}$

\section{Policy Implications}

A major shift in the organization of afterhours care has taken place in some European countries. Telephone triage and advice centers and primary care cooperatives with a variety of services have become popular over the past decade. The experiences, particularly in the Netherlands and Denmark, with primary care cooperatives integrating telephone consultations, face-to-face consultations, and house calls offer promising lessons for policymakers elsewhere.

Preliminary conclusions on the impact of this model suggest lighter workloads for doctors, fewer face-to-face contacts, and fewer house calls, all connected to fewer costs. However, there are also (yet unanswered) questions about the impact of such changes on meeting the needs of specific patient groups, about compliance with telephone advice and user satisfaction, and about continuity of care between the after-hours services and regular family physician care. Research is also inconclusive about the safety of nurse triage.

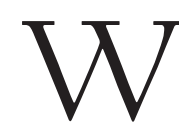
E MAY HYPOTHESIZE on the basis of current experiences that good integration, particularly at the local or regional level, of all services related to emergency and after-hours care, with exchange of information and systems for coordination and a major role for family physicians, is crucial. The optimal models need to be further developed and evaluated. 


\section{NOTES}

1. C. Schoen et al., "Taking the Pulse of Health Care Systems: Experiences of Patients with Health Problems in Six Countries," Health Affairs 24 (2005): w509-w525 (published online 3 November 2005; 10.1377/hlthaff.w5.509).

2. Ibid.

3. P. Shekelle and M. Roland, "Nurse-Led Telephone Advice Lines," Lancet 354, no. 9173 (1999): 88-89; and L. Hallam, "Out of Hours Primary Care," British Medical Journal 314, no. 7075 (1997): 157-158.

4. P.H.J. Giesen et al., "How Urgent Are the Problems Presented at a Primary Care Cooperative?" (in Dutch), Huisarts en Wetenschap 48, no. 5 (2005): 207-210; and C. Salisbury, M. Trivella, and S. Bruster, "Demand for and Supply of Out of Hours Care from General Practitioners in England and Scotland: Observational Study Based on Routinely Collected Data," British Medical Journal 320, no. 7235 (2000): 618-621.

5. Salisbury et al., "Demand for and Supply of Out of Hours Care"; V. Lattimer et al., "Future Provision of Out of Hours Primary Care: A Survey with Two General Practitioner Research Networks," British Medical Journal 312, no. 7027 (1996): 352-356; and Shekelle and Roland, "Nurse-Led Telephone Advice Lines."

6. Schoen et al., "Taking the Pulse."

7. C. van Uden, "Studies on General Practice Outof-Hours Care" (Thesis, Maastricht University, 2005); and R. Leibowitz, S. Day, and D. Dunt, "A Systematic Review of the Effect of Different Models of After-Hours Primary Medical Care Services on Clinical Outcome, Medical Workload, and Patient and GP Satisfaction," Family Practice 20, no. 3 (2003): 311-317.

8. Van Uden, "Studies on General Practice."

9. Hallam, "Out of Hours Primary Care."

10. V. Lattimer et al., "Safety and Effectiveness of Nurse Telephone Consultation in Out of Hours Primary Care: Randomised Controlled Trial," British Medical Journal 17, no. 7165 (1998): 10541059.

11. D.M. Pickin et al., "The Impact of a General Practice Co-operative on Accident and Emergency Services, Patient Satisfaction, and GP Satisfaction," Family Practice 21, no. 2 (2004): 180-182.

12. "Nurse Telephone-Triage" (Editorial), Lancet 357, no. 9253 (2001): 323.

13. J. Munro et al., "Impact of NHS Direct on Demand for Immediate Care: Observational Study," British Medical Journal 321, no. 7254 (2000): 150153.

14. J. Munro, F. Sampson, and J. Nicholl, "The Im pact of NHS Direct on the Demand for Out-of-
Hours Primary and Emergency Care," British Journal of General Practice 55, no. 519 (2005): 790-792.

15. V. Lattimer et al., "Effect of Introduction of Integrated Out of Hours Care in England: Observational Study," British Medical Journal 331, no. 7508 (2005): 81-84.

16. M.B. Christensen and F. Olesen, "Out of Hours Service in Denmark: Evaluation Five Years after Reform," British Medical Journal 316, no. 7143 (1998): 1502-1505.

17. B.L. Hansen and A. Munck, "Out-of-Hours Service in Denmark: The Effect of a Structural Change," British Journal of General Practice 48, no. 433 (1998): 1497-1499; and P. Vedsted and M.B. Christensen, "The Effect of an Out-of-Hours Reform on Attendance at Casualty Wards: The Danish Example," Scandinavian Journal of Primary Health Care 19, no. 2 (2001): 95-98.

18. Hansen and Munck, "Out-of-Hours Service."

19. Christensen and Olesen, "Out of Hours Service."

20. Van Uden, "Studies on General Practice."

21. Giesen et al., "How Urgent Are the Problems?"

22. P. Giesen et al., "Patients Evaluate Nurse Telephone Consultations in General Practice Cooperatives: Determinants of a Negative Evaluation," Patient Education and Counseling (forthcoming).

23. Ibid.

24. Ibid.

25. Giesen et al., "How Urgent Are the Problems?"

26. Ibid.

27. Ibid.

28. Ibid.

29. P.H.J. Giesen et al., "GP Cooperatives: Does the General Practitioner Benefit from Them?" (in Dutch), Huisarts en Wetenschap 43, no. 12 (2000): 508-510.

30. Ibid.

31. Van Uden, "Studies on General Practice."

32. C.J. van Uden et al., "Patient Satisfaction with Out-of-Hours Primary Care in the Netherlands," BMC Health Services Research 5, no. 1 (2005): 6. 